\title{
Insights into idiopathic pulmonary fibrosis in the real world
}

\author{
Vincent Cottin ${ }^{1}$ and Wim Wuyts ${ }^{2}$
}

\begin{abstract}
Affiliations: ${ }^{1}$ Dept of Pulmonary Medicine and National Reference Center for Rare Pulmonary Diseases, Competence Center for Pulmonary Arterial Hypertension, Louis Pradel Hospital, Hospices Civils de Lyon, Claude Bernard Lyon 1 University, Lyon, France. ${ }^{2}$ Unit for Interstitial Lung Diseases, Dept of Pulmonary Medicine, University Hospitals Leuven, Leuven, Belgium.
\end{abstract}

Correspondence: Vincent Cottin, National Reference Center for Rare Pulmonary Diseases, Louis Pradel Hospital, 28 Avenue Doyen Lepine, F-69677 Lyon, France. E-mail: vincent.cottinachu-lyon.fr

0 @ERSpublications

Prospective cohorts such as INSIGHTS-IPF are complementary to clinical trials in idiopathic pulmonary fibrosis http://ow.ly/NLvfX

Idiopathic pulmonary fibrosis (IPF) is a relentless fibrotic disorder leading to an irreversible damage of the lungs, chronic respiratory failure, and death after a median of 3 years following the diagnosis [1]. The landscape in IPF has recently been profoundly modified in a number of ways. The disease process, once considered as a chronic inflammation and treated with anti-inflammatory and immunosuppressive drugs, is now viewed as uncontrolled wound healing resulting from injury to the alveolar epithelium [2]. Epidemiological studies have showed that IPF is more common than previously appreciated in the elderly population [3], with rising prevalence and mortality [4,5]. The role of tobacco smoking is better appreciated [6]. The underlying genetic predisposition to IPF is progressively unveiled [7]. International evidence-based guidelines [8] have clarified the diagnostic approach and criteria, making large clinical studies possible, with the joined efforts of academic centres, the pharmaceutical industry, clinicians, and patients. Two antifibrotic drugs, pirfenidone and nintedanib [9-12], were recently demonstrated to reduce the progression of disease in a well-designed randomised controlled trials, and are now available to treat this dreadful disease. However, much remains to be done, before progression of IPF is controlled and the disease can be cured.

Despite the tremendous progress made, paradoxically limited information is available with regard to the natural course of disease outside clinical trials, which are admittedly biased toward selection of generally less severe disease, patients with fewer comorbidities, optimised follow-up, and most typical presentation of disease allowing inclusion. It has been shown, in a number of settings other than IPF, that patients included in clinical trials are not representative of the broader population of patients diagnosed and treated in the community throughout the world [13-15]. Many relevant questions cannot be addressed in clinical trials. Therefore, there is a need to complement data from trials by large prospective cohorts or registries that are more representative of healthcare management and the course of the disease. Several perspectives have recently emphasised the need to join efforts and to collect both data and biological material to support clinical research in the field [16, 17].

In this issue of the European Respiratory Journal, BEHR et al. [18] report on the first analysis of a prospective multicentre observational study, called INSIGHTS-IPF (Investigating Significant Health Trends in IPF) and is being conducted in Germany, in which 502 consecutive patients (including 171 newly diagnosed) were enrolled in 19 centres. IPF was diagnosed according to the current international definition $[8,19]$. The mean disease duration was $2.3 \pm 3.5$ years. Although the size of the cohort is already important, inclusion is continuing.

Received: March 052015 | Accepted: March 062015

Conflict of interest: Disclosures can be found alongside the online version of this article at erj.ersjournals.com

Copyright OERS 2015 
The authors should be commended for this important contribution to the field, with prospective inclusion, quality assurance of data, and analysis by a steering committee that is independent of the sponsor. Of note, we consider that the terminology of cohort would be more appropriate to qualify this study than that of registry, as IPF cases were probably not exhaustively included in Germany. One possible weakness of the study is that the diagnosis of IPF and decision to include into the cohort were based on an individual physician's decision and without multidisciplinary discussion for the majority of cases. Although cases were not centrally reviewed, therefore with some potential for inclusion of overlapping diagnosis, the study findings nevertheless are likely to reflect IPF as managed by interstitial lung disease (ILD) expert centres in Germany.

The main findings of this first analysis of the INSIGHTS-IPF cohort were that the functional severity of disease at diagnosis was greater than in recent randomised controlled trials. The proportion of patients who had some exposure to asbestos or to birds (56 and 19 out of 502 patients, respectively) was unexpectedly high and requires further exploration. Comorbidities were found at a high rate, illustrating differences between observational cohorts and randomised controlled trials. Interestingly, the proportion of patients who had a lung biopsy was surprisingly high, including some patients with a pattern of usual interstitial pneumonia at high resolution computed tomography, for whom biopsy may not be necessary. Only $44 \%$ of patients received pirfenidone, the only approved therapy in Europe at the time of the study, including $37 \%$ of whom had pirfenidone prescribed in combination with $\mathrm{N}$-acetylcysteine or prednisone despite the absence of evidence for combination therapy. A significant number of patients received corticosteroids, the use of which is discouraged by current guidelines. These findings imply that further educational efforts are needed to best adapt practice to state of the art knowledge and recommendations, similar to the results of a recent survey in France [20].

What can we further expect from IPF observational cohorts? It is fair to consider that lessons learned from the study by BEHR et al. [18] only represent the tip of the iceberg, and much more can be expected in coming years. As we have witnessed in the field of pulmonary arterial hypertension, cystic fibrosis, lung transplantation, lymphangioleiomyomatosis and others, prospective cohorts now represent the preferred tool to evaluate the patients' characteristics and to dissect subgroups or phenotypes that may have clinical relevance. In IPF, much can be learned from cohorts regarding evolution, and onset and impact of complications (acute exacerbations of fibrosis, pulmonary hypertension, lung cancer, etc.). Whereas randomised controlled trials aim at including the most homogeneous patient groups possible in order to maximise the chance of adequately measuring the effect size, prospective cohorts capture the heterogeneity of a disease (IPF and ILD in general are highly heterogeneous conditions) reflecting the management of patients in the "real world" and best describe the natural course of disease. IPF patients with, for example, advanced disease or those with the combined pulmonary fibrosis and emphysema syndrome, have been poorly represented in recent trials.

Although cohorts are not, by design, the appropriate tool to demonstrate efficacy of treatment interventions, they nevertheless provide the opportunity to monitor changes in disease course resulting from novel therapies or general changes in management, thereby indirectly confirming (or not) evidence from trials. One may hope, for example, that introducing antifibrotic drugs, which slow the rate of disease progression in clinical trials, may eventually translate into improved duration of survival in cohorts, with IPF becoming a truly chronic disease. This could not be addressed yet in the INSIGHTS-IPF cohort, but may be a reasonable goal in years to come. In contrast to common belief, cohorts may be suboptimal for epidemiology purposes, since registry data frequently suffer from bias due to incomplete registration, precluding measurement of true incidence and prevalence. Cohorts further provide long-term data about drug safety and tolerance, as well as invaluable information about the use of the healthcare system and induced costs including non-elective hospitalisation. By providing information about the current management, cohorts can help reducing the usage of drugs or of diagnostic procedures that are potentially harmful, and provide guidance about which educational initiatives to prioritise. This is well illustrated by BEHR et al. [18] who report that bronchoalveolar lavage and surgical lung biopsy are performed in a surprisingly high proportion of patients (62\% and 34\%, respectively), whereas multidisciplinary discussion was conducted in less than a quarter of cases.

What does the future hold? Prospective cohorts are the only way to conduct clinical research embracing the complexity of chronic diseases and will surely develop further and be crucially important in IPF. However, cohorts face many challenges and represent a major collective effort [21-25]. As there is currently a momentum to create registries at the national level in multiple countries [26], stakeholders should endeavour to share methodology with INSIGHTS-IPF so that data can be eventually combined, aiming at expand on an international global registry $[16,17]$. One further challenge will be to develop multicentre repositories of biological samples that are linked to prospective clinical cohorts, as recently emphasised [27, 28] and have already been initiated in the European IPF network initiative [16, 29]. This further increases the difficulty of the task, as it has proven difficult in the past in other areas to ensure the 
quality and completeness of both the biorepository and of the linked clinical registry. Investigators who have embarked on the INSIGHTS-IPF project may now consider combining the longitudinal clinical data with biorepositories, thereby creating an invaluable tool to tackle IPF. This would undoubtedly encourage further collaborative research between institutions and provide a resource for clinical and laboratory research, as previously envisioned [16]. Meanwhile, one immediate value of real-life cohorts and registries is to provide clinicians with a feedback of their management that is the starting point to improve daily clinical practice and to identify the next clinical research questions and hypotheses.

\section{References}

1 Ley B, Collard HR, King TE Jr. Clinical course and prediction of survival in idiopathic pulmonary fibrosis. Am J Respir Crit Care Med 2011; 183: 431-440.

2 Wolters PJ, Collard HR, Jones KD. Pathogenesis of idiopathic pulmonary fibrosis. Annu Rev Pathol 2014; 9: 157-179.

3 Nalysnyk L, Cid-Ruzafa J, Rotella P, et al. Incidence and prevalence of idiopathic pulmonary fibrosis: review of the literature. Eur Respir Rev 2012; 21: 355-361.

4 Navaratnam V, Fleming KM, West J, et al. The rising incidence of idiopathic pulmonary fibrosis in the U.K. Thorax 2011; 66: 462-467.

5 Hutchinson JP, McKeever TM, Fogarty AW, et al. Increasing global mortality from idiopathic pulmonary fibrosis in the twenty-first century. Ann Am Thorac Soc 2014; 11: 1176-1185.

6 Cordier J-F, Cottin V. Neglected evidence in idiopathic pulmonary fibrosis: from history to earlier diagnosis. Eur Respir J 2013; 42: 916-923.

7 Spagnolo P, Grunewald J, du Bois RM. Genetic determinants of pulmonary fibrosis: evolving concepts. Lancet Respir Med 2014; 2: 416-428.

8 Raghu G, Collard HR, Egan JJ, et al. An Official ATS/ERS/JRS/ALAT statement: idiopathic pulmonary fibrosis: evidence-based guidelines for diagnosis and management. Am J Respir Crit Care Med 2011; 183: 788-824.

9 Richeldi L, Costabel U, Selman M, et al. Efficacy of a tyrosine kinase inhibitor in idiopathic pulmonary fibrosis. N Engl J Med 2011; 365: 1079-1087.

10 Richeldi L, du Bois RM, Raghu G, et al. Efficacy and safety of nintedanib in idiopathic pulmonary fibrosis. $N$ Engl J Med 2014; 370: 2071-2082.

11 Noble PW, Albera C, Bradford WZ, et al. Pirfenidone in patients with idiopathic pulmonary fibrosis (CAPACITY): two randomised trials. Lancet 2011; 377: 1760-1769.

12 King TE Jr, Bradford WZ, Castro-Bernardini S, et al. A phase 3 trial of pirfenidone in patients with idiopathic pulmonary fibrosis. N Engl J Med 2014; 370: 2083-2092.

13 Cottin V, Arpin D, Lasset C, et al. Small-cell lung cancer: patients included in clinical trials are not representative of the patient population as a whole. Ann Oncol 1999; 10: 809-815.

14 Maasland L, van Oostenbrugge RJ, Franke CF, et al. Patients enrolled in large randomized clinical trials of antiplatelet treatment for prevention after transient ischemic attack or ischemic stroke are not representative of patients in clinical practice: the Netherlands Stroke Survey. Stroke 2009; 40: 2662-2668.

15 Zimmermann JB, Horscht JJ, Weigand MA, et al. Patients enrolled in randomised clinical trials are not representative of critically ill patients in clinical practice: observational study focus on tigecycline. Int J Antimicrob Agents 2013; 42: 436-442.

16 Wilson JW, du Bois RM, King TE Jr. Challenges in pulmonary fibrosis: 8-he need for an international registry for idiopathic pulmonary fibrosis. Thorax 2008; 63: 285-287.

17 Ryerson CJ, Corte TJ, Collard HR, et al. A global registry for idiopathic pulmonary fibrosis: the time is now. Eur Respir J 2014; 44: 273-276.

18 Behr J, Kreuter M, Hoeper M, et al. Management of patients with idiopathic pulmonary fibrosis in clinical practice: INSIGHTS-IPF registry. Eur Respir J 2015; 46: 186-196.

19 Behr J, Hoeper MM, Kreuter M, et al. Investigating significant health trends in idiopathic pulmonary fibrosis (INSIGHTS-IPF): rationale, aims and design of a nationwide prospective registry. BMJ Open Respir Res 2014; 1: e000010.

20 Cottin V, Cadranel J, Crestani B, et al. Management of idiopathic pulmonary fibrosis in France: a survey of 1244 pulmonologists. Respir Med 2014; 108: 195-202.

21 Agostini C, Albera C, Bariffi F, et al. First report of the Italian register for diffuse infiltrative lung disorders (RIPID). Monaldi Arch Chest Dis 2001; 56: 364-368.

22 Schweisfurth $\mathrm{H}$, Kieslich C, Satake N, et al. Wie werden interstitielle Lungenerkrankungen in Deutschland diagnostiziert? Ergebnisse des wissenschaftlichen Registers zur Erforschung von interstitiellen Lungenerkrankungen ("Fibroseregister") der WATL [How are interstitial lung diseases diagnosed in Germany? Results of the scientific registry for the exploration of interstitial lung diseases ("Fibrosis registry") of the WATL]. Pneumologie 2003; 57: 373-382.

23 Thomeer MJ, Costabe U, Rizzato G, et al. Comparison of registries of interstitial lung diseases in three European countries. Eur Respir J 2001; 32: Suppl. 32, 114S-118S.

24 Tinelli C, De Silvestri A, Richeldi L. et al. The Italian register for diffuse infiltrative lung disorders (RIPID): a four-year report. Sarcoidosis Vasc Diffuse Lung Dis 2005; 22 Suppl. 1, S4-S8.

25 Thomeer M, Demedts M, Vandeurzen K. Registration of interstitial lung diseases by 20 centres of respiratory medicine in Flanders. Acta Clin Belg 2001; 56: 163-172.

26 Moodley Y, Goh N, Glaspole I, et al. Australian Idiopathic Pulmonary Fibrosis Registry: vital lessons from a national prospective collaborative project. Respirology 2014; 19: 1088-1091.

27 Lederer DJ. Embracing complex diseases. The case for an idiopathic pulmonary fibrosis biorepository. Ann Am Thorac Soc 2014; 11: 1248-1249.

28 White ES, Brown KK, Collard HR, et al. Open-access biorepository for idiopathic pulmonary fibrosis. The way forward. Ann Am Thorac Soc 2014; 11: 1171-1175.

29 Guenther A, Eickelberg O, Preissner KT, et al. International registry for idiopathic pulmonary fibrosis. Thorax 2008; 63: 841 . 